\title{
INTERSUBJETIVIDAD ORIENTATIVA NUEVA ÉTICA EN QUE LA ACCIÓN INDIVIDUAL Y EL COMPROMISO PERSONAL NO ESTÉN DESVINCULADOS DE LOS INTERESES COLECTIVOS
}

Mónica Valencia Bolaños ${ }^{1}$

\section{RESUMEN}

La investigación se centra en quienes dirigen el proceso orientativo, su accionar en el orientado como los resultados alcanzados. Desde la premisa que la orientación es una acción social, se dirige la intención investigativa a descubrir esos episodios que hacen de ella un proceso esencialmente humano. El propósito central es desvelar un constructo teórico que constituya un nuevo episteme orientativo para el ejercicio de la carrera fundamentado en la intersubjetividad. El proceso investigativo toma cuerpo en seis puntos de inflexión: El primero, describe la realidad social del acto de la orientación tal cual como es. En un segundo, una revisión exhaustiva de la Orientación como ciencia y acción social. Tercer punto, detalla las ilaciones teóricas de la Sociología Comprensiva de Schutz (1932), el mundo de vida de
Husserl (1973) y la Acción Comunicativa de Habermas (1999). Un cuarto punto, aborda el marco metodológico estipulado en el paradigma cualitativo, desde la fenomenología como matriz epistemológica y metodológica. Además, contiene las técnicas para la obtención de las evidencias fenomenológica como la entrevista en profundidad tipo libre. Seguidamente está el quinto punto en donde se muestra el análisis de los hallazgos a través de dos vías para encontrar el significado de los datos cualitativos. Finalmente, el sexto punto de inflexión, que muestra las aproximaciones e interpretaciones realizadas para la construcción de un "Novum Corpus Teórico" en el campo de la Orientación.

Palabras clave: acción social, acción orientadora, intersubjetividad, actos de habla, cuidado de sì.

\footnotetext{
${ }^{1}$ Universidad de Carabobo, Facultad de Ciencias de la Educación, Dto. de Orientación, Valencia, Venezuela (mvalenci10@gmail.com/).
} 


\section{A MANERA DE INTRODUCCIÓN}

A partir del surgimiento de la corriente humanista SXV, la mirada investigativa se dirige hacia los factores internos de la persona, a saber: sentimientos, valores ideales, esperanzas y otros. A partir de estas premisas, se busca orientar, asistir y apoyar a los individuos a dirigir su propio desarrollo a través de capacidades característicamente humanas como la selección, la creatividad, la voluntad y la autorrealización a partir del descubrimiento y promoción de un "sí mismo".

Esta intención investigativa logró acercarse a ese cúmulo de experiencias vividas de los orientadores, sus percepciones, habilidades sociales, actitudes y aptitudes para interpretarlas y descifrarlas en relación con posturas teóricas actuales, como base para construir aportes enriquecedores de la función de ayuda y asesoramiento en el proceso de orientación educativa, con miras a responder de forma efectiva y con pertinencia social en el actual contexto riquísimo en retos, tendencias, cambios y sobre todo, incertidumbres.

Si se parte del reconocimiento del poder social del orientador y su correspondiente influencia, no queda duda al autor que esta posición privilegiada de este profesional del campo del desarrollo humano, pudiera ser maximizada, a través de la aproximación teórica de esa base de poder acercándolo a un desempeño con pericia, confiabilidad, efectividad, funcionalidad logrando con esto dar el carácter de acción a la orientación.

Es por ello que, en el marco de la composición del estudio, la investigación doctoral consta de seis partes denominadas Puntos de Inflexión (punto de no retorno), organizados de la siguiente manera:

El primero está relacionado con la presentación del hecho científico mediante la argumentación, describe la realidad social determinada tal cual, un segundo y tercer punto de inflexión, se presentan las columnas teórico-conceptuales, todo sobre la intersubjetividad, y la orientación, respectivamente. El cuarto punto, describe la vía metodológica y metódica asumidas por el autor, desde los marcos de la investigación cualitativa, con orientaciones de la Fenomenología. El quinto punto contiene el análisis de los hallazgos o evidencias fenomenológicas, con rigurosidad y exhaustividad requeridas en este tipo de investigación cualitativa basándose en la entrevista a profundidad y análisis de narrativas dialógicas. Finalmente, el sexto punto de inflexión, contiene el aporte teórico. 


\section{PRIMER PUNTO DE INFLEXIÓN: DESCRIPCIÓN DE UNA REALIDAD SOCIAL LA ORIENTACIÓN, UNA NUEVA FILOSOFÍA PARA LA RELACIONALIDAD HUMANA}

El proceso educativo en la actualidad representa un verdadero reto tanto para las comunidades gubernamentales como las civiles, el mismo está permanentemente sujeto a críticas, evaluaciones, transformaciones y al parecer, ningún cambio responde a las necesidades de la época. En la presente, la sociedad del conocimiento y la era de la información ha sido mucho más desvalorizada; se ha intentado incluso sustituir la misma naturaleza humana de la educación, por la virtualidad y la poderosa influencia de las tecnologías de información.

Sin duda, la educación tiene un fin social, la escuela no termina en sí misma (Alonso: 2006-44), sino que funciona como un trampolín para la vida. Es para ella que se enseña, se forma, se aconseja, e incluso se yerra. Esta realidad obliga a estudiar la vida, la sociedad, la cultura y principalmente al individuo.

Sin embargo para nuestros tiempos, los episodios citados son juzgados duramente por un incisivo Savater (2000:13), quien toma las angustias de Juan Carlos Tedesco, sobre la crisis de la educación. Él afirma que ya no es lo que era esta crisis, considera que no proviene de la deficiente forma en que la educa- ción cumple con los objetivos sociales que tiene asignados, sino que, es más grave aún, no se sabe qué finalidades debe cumplir y hacia dónde efectivamente debe orientar sus acciones. Probablemente ya no solo se reduce esta problemática al fracaso de un puñado de estudiantes, ni tampoco los innumerables conflictos socio-educativos propios en los contextos actuales, sino que al parecer, es mucho más siniestro: se visualiza el desdibujamiento de la naturaleza de sus fines.

Así, dentro de la cosmovisión educativa, está imbricada la Orientación. Luego, ¿quién orienta a quién, la escuela solo educa y no orienta o sí lo hace? ¿La construcción de la persona es obra solamente de la educación? ¿Las corrientes educativas deben contener visiones integrales donde vinculen el conocer con el ser, el convivir y la participación? ¿Los agentes socializadores qué tan responsables son del hombre actual? ¿La orientación es un proceso de humanización dentro del de socialización?

La orientación es una de las Ciencias de la Educación en donde el conocimiento del otro es esencial, la realidad de nuestros semejantes, la percepción al considerarles sujetos y no objetos, pro- 
tagonistas de su vida y no meros títeres de las circunstancias (Rogers 1902-1987) constituye una misión en sí misma y una tarea. El orientador requiere comprender que el destino de cada ser humano, incluso el suyo mismo, no es solamente la cultura, ni siquiera estrictamente la sociedad, en cuanto a institución, sino los semejantes. "Solamente en el comercio intersubjetivo con los semejantes se aprende significados" Sabater (2000:31).

El ser humano, enfrentado a una realidad impresionantemente diversa, compleja y dinámica, con avances y miserias de dimensiones nunca vistas, con realidades sociales conflictivas y con deslumbrantes hiperrealidades simuladas desde los medios audiovisuales constituye un laberinto en medio del cual las personas circulan en estados de confusión, bloqueo, faltas o carencias, abandono o locura social. Desde estos horizontes, cabe indagar ¿cómo se desarrolla la orientación?, probablemente hay nuevas formas de construirse y precisamente este, como otros especialistas del comportamiento humano, está sujeto a desplazar sus estrategias de intervención y/o medición en este nuevo hombre.

En este sentido, para Foucault (1994:3) esta construcción tiene que ver con una actitud en general de estar en el mundo, realizar acciones, tener relaciones con el prójimo. Él inserta la "epimeleia heautou" (término estonio sin traducción al español) que es una actitud: con respecto a sí mismo, con respecto a los otros, con respecto al mundo. Esa actitud parte de una serie de fórmulas como "ocuparse de sí mismo", "cuidar de sí," "retirarse hacia sí mismo", "retrotraerse en sí mismo", "complacerse en sí mismo", "no buscar otra voluptuosidad que la que hay en uno mismo", "permanecer en compañía de sí mismo", "ser amigo de sí mismo", "estar en sí mismo como en una fortaleza", "cuidarse" o"rendirse culto", "respetarse", entre otros. Con esto carga una gran preponderancia de la propia subjetividad para pasar inmediatamente a la intersubjetividad.

\section{SEGUNDO PUNTO DE INFLEXIÓN: ILACIONES TEÓRICAS. LA ORIENTACIÓN EDUCATIVA PERSPECTIVAS EN EL TIEMPO Y EN EL ESPACIO}

Con el fin de comprender, los fundamentos contextuales de la Orientación, se hace necesario identificar los antecedentes históricos de esta práctica socioeducativa en aquellas latitudes donde se institucionalizó: Estados Unidos y Europa. La práctica de la Orientación se establece debido a unas condiciones contextuales específicas que la convierten en un área educativa nece- 
saria, útil y pertinente. Según Álvarez y Bisquerra (2005) en un breve recorrido sobre su historia reseña a varios autores entre los cuales están: Parsons (1909) concibió la Orientación como la adecuación del sujeto al trabajo. Proctor (1925) la define como proceso de distribución (formular metas, conocimiento propio y del entorno) y ajuste. Según Brewer (1932) la Orientación se identifica con la educación. Williamson (1939) pone el énfasis en las bases diagnósticas de la Orientación. Shoben (1962) la planteó como una reforma social, con el orientador como líder de esta «reconstrucción». Para Miller (1971) la Orientación es el proceso por el que se ayuda a los individuos a lograr la autocomprensión y autodirección necesarias para conseguir el máximo ajuste a la escuela, al hogar y a la comunidad. Mathewson (1962) concibe la Orientación como proceso de desarrollo. Adschuier (1969), Mosher y Sprinthall (1970, 197l), Cottinghan (1973) e Ivey y Alschuler (1973), entre otros, la denominan educación psicológica.

En virtud de ello, Álvarez y Bisquerra (Cit.Ob.) citan además a Hoyt, (1978, 1985) que a partir de los años setenta ha tenido una especial relevancia el movimiento de Educación para la Carrera. Estos autores citados, afirman que muchos autores actuales tienden a poner el énfasis en la prevención como: (Baker y Shaw, 1987; Botvin y Dusenbury, 1987; Conyne, 1987) o en el desarrollo (Hayes y Aubrey, 1988; Myrick, 1987). De esta forma, los autores concluyen que la multiplicidad de teorías a veces ha provocado disputas partidistas entre los respectivos militantes. De allí la importancia que tiene el último criterio de Beck (1973), el cual afirma que todos los autores citados anteriormente parecen coincidir en que el fin de la orientación no solo es la solución de problemas, sino la ayuda para lograr la autoorientación y el desarrollo personal, premisa que coincide con esta investigación.

Centrados en este enfoque, durante el siglo XX, el dinamismo cultural, social y sobre todo los avances de la ciencia, la tecnología y la comunicación marcaron pautas paradigmáticas para el ejercicio docente. Así en Orientación, se asume el paradigma del Desarrollo Humano como el medio para el desarrollo de las potencialidades de la persona, en su plenitud, tanto en su dimensión personal, como familiar, social. A finales de este siglo, la Organización de las Naciones Unidas, para la Educación, la Ciencia y la Cultura (UNESCO, 1998), formaliza este paradigma como elemento fundamental para la Educación Superior del Siglo XXI. 


\section{TERCER PUNTO DE INFLEXIÓN: ILACIONES TEÓRICAS. LA ACCIÓN COMUNICATIVA Y LA INTERSUBJETIVIDAD. EL HORIZONTE DE LA OTREDAD}

Para el abordaje de la acción comunicativa y la intersubjetividad, se hace perentorio un paso primero en la subjetividad del ser humano, tomando una premisa base, la que afirma: el hombre es un ser humano, y todo ser como tal posee una lógica propia de existencia: nace, se alimenta, crea un medio propio de reproducción como de mantenimiento y muere. Logra así su propio criterio de existencia, o de realidad. El hombre es un ser corporal, la vida, su contexto; las circunstancias, el libreto y sus vivencias, sentimientos, sensaciones, el mundo interno o subjetivo.

Este ser protagonista, tiene un elemento que lo hace único en este contexto, su corporalidad, ésta tiene un centro nervioso que le permite experimentar estímulos, sensaciones o impresiones de fuera hacia adentro. Es decir, que a través de su piel, este sujeto siente dolor, placer, sensaciones, emociones y un sinnúmero de vivencias internas que salen de él, provocando todo tipo de expresiones que pueden ser incluso adversas a sí mismo. Al respecto Dusser (1999) describe a ese mundo subjetivo de la siguiente manera:

La subjetividad es un momento de la corporalidad humana. Es el momento en el que toda la corporalidad hu-

\begin{abstract}
mana es considerada desde la indicada perspectiva "interior" no es una metáfora, ya que la "interioridad" de la corporalidad humana es todo lo que acontece "desde debajo de la piel"; lo demás es el campo de lo real (omnitudo realitatis) que se presenta "afuera" bajo la luz en el "estado de vigilia"La subjetividad es más que consciencia, pero dice referencia a ella. Es el "vivenciar" lo que acontece (físicamente transmitido por el sistema nervioso) en la realidad (págs. 3/18).
\end{abstract}

De tal forma que, una referencia básica al hablar de subjetividad es la interioridad, relativa al mundo vivido desde adentro hacia afuera, desde lo físico (piel, músculos, células, glándulas, órganos, y demás) generando no solamente, respuestas orgánicas funcionales, sino sensaciones, sentimientos, ideas, pulsiones que a su vez generan otras vivencias.

En este preciso episodio, cuando surge y se reconocen esas nuevas vivencias, también aparece el "Otro", como un hecho interior por excelencia (visión fenomenológica), por el que la corporalidad se sitúa como una experiencia vivida en donde surgen las vivencias en sí, las cosas, los objetos. Dusser (Cit.Ob.) lo explica así: 
La corporalidad de cada ser humano es un momento de la comunidad humana. La comunidad humana constituye en cada nivel una referencia necesaria y coimplicante. Mi propia corporalidad ha nacido dentro de la especie humana, dentro de un pueblo, una familia; mi madre me ha parido. Esto indica todo el problema genético, la referencia ecológica terrestre, la historia biológica de una especie. Pero, además, mi subjetividad está constituida intersubjetivamente, desde el punto de vista lingüístico, cultural (valores), social (instituciones), histórico (tradiciones), etc (pags. 5/18).

Desde este contexto, el ser humano individual es a la vez plural, se constituye un ser solamente con el otro, es decir, mantiene una suerte de referencia existencial con una comunidad de pares. Es por ello que al hablar de subjetividad está implícita la intersubjetividad. Esta situación de relacionalidad eminentemente social, se puede enfocar desde varias corrientes filosóficas, a saber:

Edmundo Husserl (1859-1938) en la primera mitad del pasado siglo XX y aún vigente en el interés de los estudiosos. El citado por Derridá (1967) el cual adelanta la tesis central de la Fenomenología: "La filosofía de Husserl es el verdadero positivismo que vuelve a las cosas mismas y desaparece ante las originalidades, pues en efecto la Fenomenología busca captar los objetos (las cosas mismas) como son dados directa- mente a la conciencia por la experiencia sin implicarse en la conceptualización. El observador se propone como un ente pasivo que se suspende (epogé) se abstiene de ir más allá del acto de captar en la conciencia, de tender hacia un objeto, acción que en Fenomenología se denomina Intencionalidad (concepto que Husserl toma de Franz Brentano que fue profesor suyo). Toda conciencia es siempre conciencia de algo. La presencia de un objeto en la conciencia implica que ese algo está presente en ella aunque tal presencia no se conceptualice. A ese acto de captación directa del objeto sin posterior conceptualización, le llama Husserl, Reducción Eidética.

En síntesis la intersubjetividad es posible en los contextos orientativos porque el mundo del sentido común permite anticipar ciertas conductas para desarrollar la vida social, la misma que se puede evidenciar cuando el asesor se dirige a un orientado y le pregunta sobre algún tema, él estaría suponiendo una estructura social en la que reconoce al otro, y asume que comparte ciertos códigos, se une a ellos en alguna actividad común, influiría y el otro se dejaría influir, es decir un intercambio de actitudes, búsquedas y posiciones de intenciones de aprendizaje e interaprendizaje.

En lo referente a la teoría Acción Comunicativa de Habermas (1999) propone un modelo teórico que permite 
analizar la sociedad con dos formas de racionalidad que están en juego simultáneamente: la racionalidad sustantiva del mundo, de la vida y la racionalidad formal del sistema; la primera, es donde se representa una perspectiva interna como el punto de vista de los sujetos que actúan sobre la sociedad, mientras que en la segunda representa la perspectiva externa, como la estructura sistémica (la racionalidad técnica, burocratizada-weberiana, de las instituciones).

Estos postulados de Habermas (Cit.Ob.) como la racionalidad, la acción comunicativa, racionalidad moral, la in- tersubjetividad, mundo de vida entre otros son aristas que dirigieron las respectivas interpretaciones y análisis de la modernidad en la que se desenvuelve el orientador educativo, en la cual, "habermasianamente" hablando, se dan tipos de patologías sociales que actualmente se van tornando cada vez más comunes y a las que se enfrenta y debe abordarlas, intervenirlas, orientarlas y reorientarlas. En mis términos, la teoría de la acción comunicativa permitió una minuciosa categorización del plexo de la vida socioeducativa, con la que se podrá dar alguna razón de las paradojas de la modernidad.

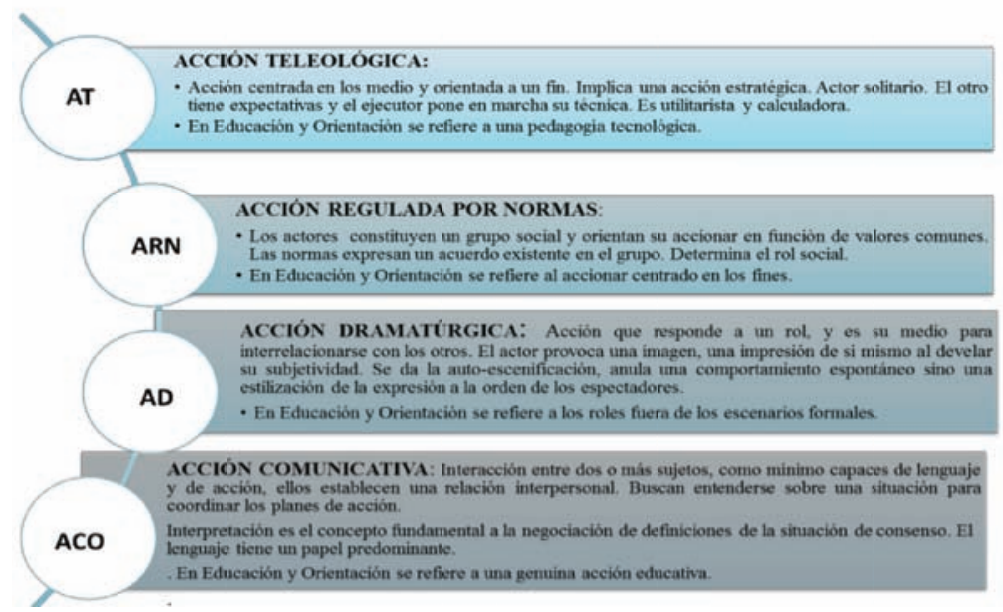

\section{Gráfico n. ${ }^{\circ}$ 1-Tipos de Acciones Sociales según Habermas (1999)}

Fuente: Habermas (1999) Adatado por Valencia, M. (2013). 


\section{CUARTO PUNTO DE INFLEXIÓN: LA METODOLOGÍA Y METÓDICA INVESTIGATIVA. UNA VÍA PARA LA CIENTIFICIDAD DE DATOS CUALITATIVOS}

a. Exploración inicial del problema a estudiar

\begin{tabular}{|c|c|c|c|}
\hline $\begin{array}{c}\text { Descripción de la realidad } \\
\text { social }\end{array}$ & $\begin{array}{c}\text { Exploración contextual e } \\
\text { intertextual de los hechos socio } \\
\text { educativos tal comoson }\end{array}$ & $\begin{array}{c}\text { Captación de los enfoques } \\
\text { de las realidades sociales }\end{array}$ & $\begin{array}{c}\text { Especificidad de la realidad } \\
\text { social como fenómeno social }\end{array}$ \\
\hline
\end{tabular}

b. Participación del investigador en el medio social a investigar

Determinación de la realidad mental o constituyente

Exploración de la realidad social, actores sociales,

con marco referencial para una interacción dialéctica actos sociales posibles sujetos a interpretación.

\section{c. Uso de técnicas propias de la investigación cualitativa}

\begin{tabular}{|l|c|}
\hline Definición metodológica del enfoque cualitativo investigativo & $\begin{array}{c}\text { Definición de técnicas base: } \\
\text { la entrevista a profundidad y análisis del relato }\end{array}$
\end{tabular}

\section{d. Marco interpretativo}

Seleccionar las estructruras teóricas adecuadas para crear epistemes significantes en el ámbito socio - educativo - orientativo

\section{e. Resultados escritos}

Proceso de decantación del material obtenido para detectar realidades, matices, acentos, versiones, actitudes, percepciones. Ubicación de los verbos, adjetivos, adverbios que den la significatividad contextual e intracontextual

\section{f. Teorización}

Crear ciencia, ver el hecho socioeducativo desde la percepción cualitativa fenomenológica por medio de un arte constructivista logrando un todo coherente, lógico, que sintetice los referentes teóricos, las experiencias vividas contrastando y pariendo posturas científicas.

\section{Cuadro $n .^{\circ}$ 1. Pasos de la metódica cualitativa-fenomenológica}

Fuente: Martínez (2004) Adaptado por Valencia M. (2013). 


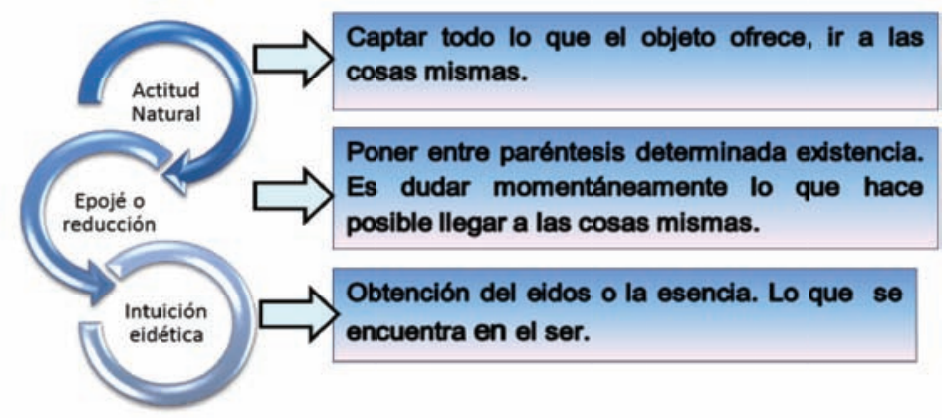

Gráfico n. ${ }^{\circ}$ 2. Pasos del método fenomenológico según Husserl Fuente: Chávez (2004) Adaptado por Valencia, M. (2013).

Técnicas de investigación cualitativa

Son dos técnicas que se aplican con una visión de complementariedad: a. Entrevista en profundidad libre: Claret 2008.

b. Análisis dialógico: Mayring (1983), Riessman (2008), Labov citado por Coffey (2003).

\section{Cuadro n. ${ }^{\circ}$ 2. Guía proceso para la entrevista en profundidad libre}

\section{GUÍA PROCESO PARA LA ENTREVISTA EN PROFUNDIDAD LIBRE}

\section{Elaboración del guión:}

- Longitud de la entrevista: libre

- Naturaleza de las preguntas: inicial-generadora a la conversación

- Naturaleza de la investigación: cualitativa- indagatoria

- Tipo de hallazgos: narrativa dialógica

\section{Fase Introductoria:}

- Fin de la entrevista: contacto con orientadores y sus experiencias desde su propia vida académica universitaria

- Carácter: confidencial

- Modalidad de colaboración: solicitada por la investigadora previa cita

\section{Desarrollo}

- Dar a conocer la intencionalidad investigativa

- Dirigir la conversación de forma libre y direccionada a la vez

- Aprovechar el discurso para afianzar temas de interés

- Cerrar de forma grata, elegante y cordial

- Dejar la posibilidad de nuevas entrevistas 
Dentro de este orden, la segunda técnica, tanto Mayring (1983) como Riessman (2008) señalan al análisis narrativo desde términos cualitativos como la historia en sí, es decir, el relato de una secuencia de acontecimientos que tienen especial importancia para el narrador, como para el investigador. Dicho relato tiene una estructura determinada, un comienzo, una mitad y un final, con una lógica para el narrador. Visto desde esta perspectiva, la narración de hechos vividos por sus propios actores, para su respectivo análisis fenomenológico, es lo que Riessman (Ob.Cit) denomina el "giro interpretativo" en la investigación cualitativa y lo que fundamentalmente la autora aplica con una visión social tan profunda, que logra aportar una etnometodología.

Así mismo, se toman las consideraciones de Coffey (2003), cuando cita a Labov quien sostiene que las narrativas y relatos tienen funciones sociales con propiedades estructurales y formales en donde se identifican patrones recurrentes que se pueden interpretar a través de las formas cómo cuenta la gente sus historias, del modo en que lo hacen, cuando dan forma a los acontecimientos que relatan, cómo hacen para mostrar sus ideas, cómo empacan los eventos narrados, y sus reacciones a ellos, y cómo articulan las narrativas con el investigador.

\section{QUINTO PUNTO DE INFLEXIÓN: \\ ANÁLISIS DE LA INFORMACIÓN, TRATAMIENTO Y SIGNIFICADO FENOMENOLÓGICO. ANÁLISIS DE CONTENIDO Y NARRATIVA, UNA VÍA DE TRATAMIENTO EN PROFUNDIDAD}

\section{Cuadro n. ${ }^{\circ}$ 3- Protocolización y organización del contenido de entrevistas según Mayring (1983)}

\begin{tabular}{|ll|}
\hline FASES & \multicolumn{1}{c|}{ DESCRIPCIÓN } \\
\hline Primera & $\begin{array}{l}\text { Seleccionar las entrevistas o las partes relevantes para responder a los objetivos } \\
\text { de la investigación. }\end{array}$ \\
\hline Segunda & $\begin{array}{l}\text { Analizar la situación de recogida de datos, es decir cómo se generó el material, } \\
\text { quién o quiénes estuvieron implicados, de dónde proceden los hechos. }\end{array}$ \\
\hline Tercera & Caracterizar el material o diseñar el modelo de análisis formal de información. \\
\hline Cuarta & $\begin{array}{l}\text { Direccionar el análisis de los textos o párrafos de las entrevistas, los cuales deben } \\
\text { hacerse en función de los propósitos de la investigación. }\end{array}$ \\
\hline
\end{tabular}

Fuente: Mayring (1993). Adaptado por Valencia, M. (2013) 


\section{Cuadro n. ${ }^{\circ}$ 4-Modelo de Evaluación de Labov (2003)}

\begin{tabular}{|ll|}
\hline $\begin{array}{l}\text { UNIDADES DE ANÁLISIS } \\
\text { (ESTRUCTURA }\end{array}$ & $\begin{array}{l}\text { PREGUNTAS DETECTORAS } \\
\text { DE SIGNIFICADOS) }\end{array}$ \\
\hline Resumen & ¿De qué trata? \\
\hline Orientación & ¿Quién? ¿qué? cuándo? ¿cómo? \\
\hline Complicación & ¿Entonces qué sucedió? \\
\hline Evaluación & ¿Y entonces qué? \\
\hline Resultado & ¿Finalmente qué pasó? \\
\hline Coda & ¿Cómo termina la narrativa? \\
\hline
\end{tabular}

Fuente: Coffe y Atkinson (2003:69) adaptado por Valencia, M. (2013)

\section{Cuadro . $^{\circ}$ 5-Unidades de análisis.- Definición}

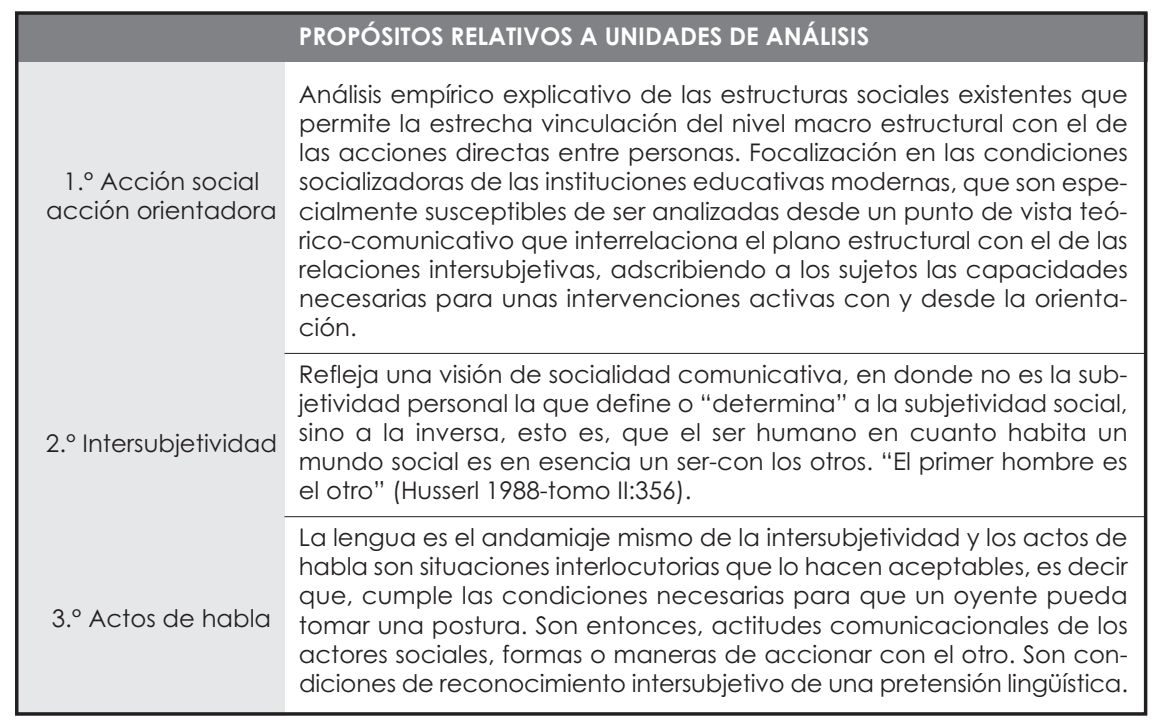

Fuente: Valencia, M. (2013). 


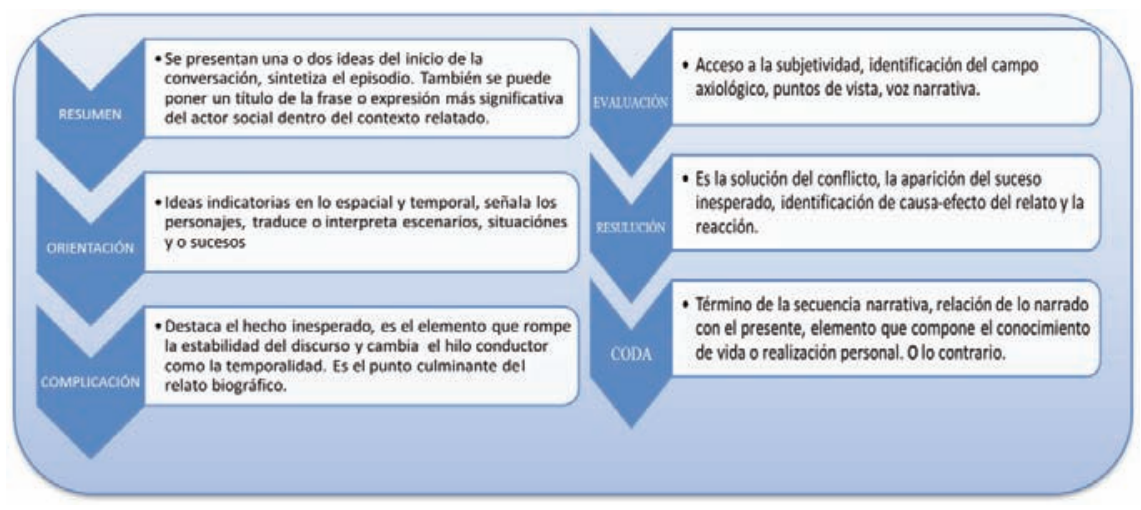

\section{GRÁFICO n. ${ }^{\circ}$ 3. SEGUNDO NIVEL DE ANÁLISIS SEGÚN RIESSMAN Y LABOV}

Fuente: Riessman y otros (2003) Adaptado por Valencia, M. (2013)

Este análisis se desarrolló con cada uno de los informantes claves, obteniendo sistemática y producativamente las dimensiones dialógicas más ricas en las narraciones de cada uno de ellos, así. relaciones de poder, niveles de racionalidad, roles, episiodios significativos, entre lo más resaltante, se resume la frase que de su propio discurso se ob- tuvo con la que se identifican en su existencia:

DOR: "NACI CON LA NECESIDAD DE AYUDAR"

DFA: "EPA...LÍDER..YA VIENE EL LÍDER"

DLFS: "NO SOY YO...SOY EL COLECTIVO"

\section{SEXTO PUNTO DE INFLEXIÓN: NOVUM CORPUS TEÓRICO}

\section{EL"Novum Corpus" (Cuerpo Nuevo)} teórico para la intermediación de una comunidad intersubjetiva, es preciso reflexionar sobre las bases de una nueva ética en la que la acción individual y el compromiso personal no estén desvinculados de los intereses colectivos. En este orden, se construye el establecimiento de otros modos de pensar, poder, saber, ser, sentir, comunicar, escuchar para una sociedad de convivencia del buen vivir, que libere al hombre de esos contenidos que los ata a cadenas mezquinas, dándole la dirección justa a 
sus potencialidades, para ello, se demarcan varias inspiraciones tomadas del análisis en profundidad de las evidencias fenoménicas presentadas en los partes anteriores, y son (en documento doctoral están presentadas y desarrolladas):

\section{La"epimeleia heautou". El compro-} miso personal vinculado al colectivo.

2. La búsqueda del buey. Vías para la comprensión de la individuación.

3. El diálogo que somos. El orientador hermeneuta en la formación de seres dialógicos, un desafío en los procesos de vinculación actuales.

En fin... la Orientación universitaria bajo estas aristas, implica la libación de la particularidad a favor de la generalidad, más bien, de la otredad. Los agentes sociales que forman para y por el diálogo, padres, escuela, docentes, orientadores se enfrentan a esta realidad cruda en donde el principio de la individualidad es lo que prima, el reto es recuperar el humanismo gadameriano, es aprender a escuchar, en contra del ensimismamiento; es eliminar el personalismo y el afán de imposición de todo impulso vanidoso que genera el intelecto egoico.

Para finalizar, en la ostentación vanidosa de educadores y orientadores, al creer que somos capaces de educar a otros, es obligante apropiarse de las tesis gamerianas, ya que en el trato con las personas hay que mantenerse abierto al entendimiento, y eso implica consideración, tolerancia, respeto y humildad frente al otro; sin estos elementos la maravillosa aventura del interaprendizaje se convierte en una quimera. Lo planteado nos lleva a afirmar que todos educamos a todos, y aun sin quererlo lo hacemos, lo importante es asumir como orientadores responsablemente y con conocimiento, este rol de humanizadores en la comunidad, parroquia, institución educativa, familia, para dar cuenta de ello a las generaciones presentes y a futuro.

Tanto es así, que el hombre es definido como ser dialógico, un ser capaz de entrar en conversación, sobre todo un ser lingüístico, por estar provisto de la lengua como auténtico vínculo de comunicación con los demás. Para Gadamer, existe una "lingüisticidad" original de nuestra experiencia hermenéutica, experiencia interpretativa-del mundo, por ende, suscribimos la experiencia como la del dios griego Hermes, mediar entre los seres humanos para no olvidarnos que lo somos. 


\section{BIBLIOGRAFÍA}

Alonso, J. (2007). Manual de Orientación Educativa y Tutoría. Tercera Edición. Universidad La Salle y Plaza y Valdés, S.A. de Madrid, España.

Alvarez, M. y Bisquerra, R. (2005). Manual de Orientación y Tutoría. Barcelona: Praxis.

Aristóteles, (1973). Obras completas. Madrid (nemo compilación) Documento www. Disponible [www.aristoteles/obrascompletas.com]

Asamblea Nacional Constituyente (2009). Ley Orgánica de Educación. Gaceta Oficial n. 5929 del 15 de agosto de 2009. Editorial La Piedra Caracas, Venezuela.

Asamblea Nacional Constituyente (1999). Constitución de la República Bolivariana de Venezuela. Gaceta Oficial 36.860 Del 30 de diciembre de 1999. Editorial Nabriel Caracas, Venezuela.

Bisquerra, R. (2002). Modelos de Orientación e Intervención Psicopedagógica. BarceIona: Praxis Universidad.

Claret, A. (2008). Proyectos Comunitarios e Investigación Cualitativa. Segunda Edición. Editorial Texto, C.A. Caracas, Venezuela.

Chávez, P. (2004). Historia de las doctrinas filosóficas. Tercera Edición. Editorial Pearson Educación. México.

Derridá, J (1967). Génesis y estructura y la fenomenología. Conferencia pronunciada en Cerisy La Salle en 1959. Publicada en el volumen Genesys y estructura dirigido por MM de Gandillac, L. Goldmann y J. Piaget, Mounton 1964. Publicada por último en Lécriture et la Difference. Colección Criteque, Paris, Minuit, 1967. Documento web disponible en (http://www.jacquesderrida.com.ar/ index.htm]

Dussel, E. (1999). Sobre el sujeto y la intersubjetividad: el agente histórico como actor en los movimientos sociales. Publicado en Revista Pasos n. ${ }^{\circ}$ 84-Segunda Época 1999: julio-agosto. [Documento WWW] Disponible en www.intersubjetividad.com.ar Consulta: 16-06-2012

Egan, G. (1994). El orientador experto: un modelo para la ayuda sistemática y la relación interpersonal. Grupo Editorial iberoamericana, S.A. de C.V. Versión español. Distrito Federal, México

Estrada, M. (1995). Participación política, actores colectivos. Primera edición. Editorial universidad iberoamericana. México. DF. Gadamer, H.G. (1993) Verdad y Método I. Fundementos de una hermenútica Filosófica. Hermeneia. Quinta Edición. Ediciones Sígueme. Salamanca España. Gadamer, H.G. (2000) Educar es Educarse. Editorial Paidos. BarceIona, España.

Habermas, J (1999). Teoría de la Acción Comunicativa, I. Racionalidad de la Acción Y Racionalización Social. Cuarta Edición. Grupo Santillana de Ediciones S.A. Editorial TaurusSantafé de Bogotá, Colombia 
Husserl, E. (1973). El Problema de la Realidad Social. Buenos Aires: Amorrortu, 1973, Traducción del libro original Collected Papers: The Problem Of Social Reality, de 1962).

Mayring. F. (1993). Análisis social del contenido cualitativo. [Documento WWW] Disponible en: http://www.qualitative-research.net/index.php/fqs/article/vie

Ministerio del Poder Popular para la Educación Superior (2009) Mesa Técnica Nacional. Proyecto: Sistema Nacional de Orientación. Documento Oficial DOP-2009-01. [Documento WWW] Disponible en: www.mes.gov.ve/documentos/descarga/pd f18-12-2009_11:28:58.pdf
Riessman, C. (2008). Métodos narrativos para las Ciencias Humanas. CA, EE.UU.: SAGE Publications, 244 páginas, ISBN: 978-0-76192998-7, EE.UU.[DocumentoWeb] Disponible en http://www.qualitative-research.net/in dex.php/fqs/article/view/1418/2906

Rogers, C. (1969). Psicoterapia centrada en el cliente. Buenos Aires: Paidós.

Savater, F. (2000). El Valor de Educar. Décima primera reimpresión. Bogotá, Colombia. Editorial Ariel S.A.

Schültz, A. (1993). La Construcción significativa del Mundo Social. Introducción a La Sociología Comprensiva, Ediciones Paidós 